\title{
A FORÇA LEGAL DO TÍTULO DE CRÉDITO EMITIDO ELETRONICAMENTE NO ORDENAMENTO JURÍDICO BRASILEIRO
}

THE LEGAL FORCE OF CREDIT TITLE ISSUED ELECTRONICALLY IN BRAZILIAN LEGAL ORDINATION

Clareana Isaac RODRIGUES ${ }^{1}$

Marília Benedini PEREIRA²

ISSUE DOI: $10.21207 / 1983.4225 .580$

\section{RESUMO}

$\mathrm{O}$ advento da Internet tem trazido mudanças substanciais nos relacionamentos interpessoais. Consequentemente, na esfera do Direito, novas relações jurídicas vêm sendo estabelecidas digitalmente. Neste artigo, pois, propomos uma análise acerca da emissão de títulos de crédito eletrônicos, utilizandonos das mais recentes lições doutrinárias, jurisprudenciais e de artigos jurídicos sobre o tema, para concluir sobre sua existência, possibilidade, força probante e executividade na conjuntura legal nacional.

Palavras-chave: Títulos de Crédito Eletrônicos. Desmaterialização. Princípio da Cartularidade. Duplicata Virtual. Cheques Eletrônicos. Execução de Títulos Imateriais.

\section{ABSTRACT}

The advent of the Internet has brought substantial changes to interpersonal relationships. Consequently, in the legal area, new juridical relations have been digitally stablished. In this article, then, we propose an analysis about the emission of eletronic credit titles, making use of the most recent

${ }^{1}$ Cursando o $4^{\circ}$ Ano Diurno da Faculdade de Direito de Franca, em Franca/SP. Estágio no Tribunal Regional do Trabalho da $15^{\text {a }}$ Região - Vara do Trabalho de Batatais - SP.

${ }^{2}$ Cursando o $3^{\circ}$ Ano Diurno da Faculdade de Direito de Franca, em Franca/SP. Estágio no Tribunal Regional do Trabalho da $15^{\text {a }}$ Região - Vara do Trabalho de Batatais - SP. 
doutrinary and jurisprudential lessons and juridical articles about the theme, in order to get to a conclusion about their existence, possibility, probing forces and executivity in the national legal structure.

Keywords: Eletronic Credit Titles. Dematerialization. The Cartularity Principle. Virtual Invoice. Eletronic Checks. Imaterial Titles Execution.

\section{INTRODUÇÃO}

Na Idade Média, devido à circulação pecuniária e com a finalidade de proteger o patrimônio de credores e devedores, sugiram os títulos de crédito, que se popularizaram em razão do surgimento do comércio e da segurança que trouxeram aos seus titulares. Nesse contexto, o primeiro cambial conhecido pelo homem foi a letra de câmbio ${ }^{3}$.

A partir da letra de câmbio, outros títulos sucederam, como a nota promissória, o cheque e a duplicata. Todos eles evoluíram juntamente com a humanidade para atender às suas necessidades, até os dias atuais, em se fala em sua desmaterialização, principalmente em virtude do comércio eletrônico.

O conceito de título de crédito mais conhecido e aceito entre os doutrinadores é o de "documento necessário para o exercício do direito, literal e autônomo, nele mencionado", o qual se encontra intimamente vinculado aos seus princípios regentes: a cartularidade, agora afastada pela virtualização concebida pela Internet, a literalidade e a autonomia.

Não obstante, o referido progresso trouxe dúvidas antes inexistente no Direito, tais como a maneira pela qual ocorre a emissão e execução de tais títulos eletrônicos e, ainda, como se comporta o princípio básico da cartularidade em meio a tantas mudanças. O presente artigo pretende, portanto, esclarecer essas questões que permeiam o ordenamento jurídico brasileiro.

\section{A EMISSÃO DE TÍTULOS DE CRÉdITO VIRTUAIS COMO DOCUMENTOS}

\footnotetext{
${ }^{3}$ RAFIH, Rhasmye El; CABRIOLI, José Vinicius. Origem e evolução dos títulos de crédito. Revista Jus Navigandi, ISSN 1518-4862, Teresina, ano 20, n. 4277, 18 mar. 2015. Disponível em: <https://jus.com.br/artigos/32014>. Acesso em: 24 abr. 2017

${ }^{4}$ VIVANTE, Cesare. Instituições de direito comercial. Trad. J. Alves de Sá. 3.ed. São Paulo: Livraria C. Ponto Teixeira \& C. ${ }^{\text {a }}$. 1928. p. 136.
} 
É notório que as sociedades estão em constante evolução. Como consequência, a tecnologia se encontra continuamente em igual processo de modernização. Daí que, tendo o Direito a importante missão de procurar disciplinar as situações socialmente relevantes criadas pelo avanço dos tempos, não poderia ignorar as novas relações jurídicas originadas da prática, agora virtual, de atos como a emissão e a circulação de documentos, incluindo-se, nesse rol, os títulos de crédito.

Nesse sentido, o Código Civil brasileiro (Lei 10406/02) inovou ao trazer, em seu artigo $889, \S 3^{\circ}$, que "o título poderá ser emitido a partir de caracteres criados em computador ou meio técnico equivalente e que constem da escrituração do emitente, observados os requisitos mínimos previstos neste artigo". Configuram-se os referidos requisitos, conforme artigo 889, caput, como "a data da emissão, a indicação precisa dos direitos que confere, e a assinatura do emitente".

Sem embargo, o necessário atendimento a tais pressupostos traz naturalmente uma preocupação acerca da possibilidade de manter-se a veracidade, a autenticidade e a integridade de tais documentos. Para tal finalidade, foi criada pela Medida Provisória n. 2.200-2/2001 5 a Infraestrutura de Chaves Públicas Brasileira (ICP-BRASIL) Gestor, vinculado à Casa Civil da Presidência da República, uma Autoridade Certificadora Raiz, qual seja o Instituto de Tecnologia da Informação (ITI) e uma rede de Autoridades Certificadoras e Autoridades de Registro ${ }^{7}$, que "mantêm os registros dos usuários e atestam a ligação entre as chaves privadas utilizadas nas assinaturas dos documentos e as pessoas que nelas apontam como emitentes das mensagens, garantindo a inalterabilidade dos seus conteúdos"8.

Além disso, para proteção contra possíveis ações fraudulentas, foram criados os institutos da assinatura digital e da certificação eletrônica. Sobre o primeiro, Ricardo Negrão (2012, p. 48), cita os ensinamentos de Francisco Eduardo Loureiro (2004, p. 367), que aponta que esse:

\footnotetext{
${ }^{5}$ BRASIL. Medida Provisória no 2.200-2, de 24 de agosto de 2001. Diário Oficial da República Federativa do Brasil, Poder Executivo, Brasília, DF, 27 de ago. 2001. Seção 1, p. 65.

${ }^{6}$ Informação fornecida pelo Instituto Nacional de Tecnologia da Informação. Disponível em: <http://www.iti.gov.br/icp-brasil>. Acesso em: 05 set. 2017.

${ }^{7}$ Rede de autoridades listadas pelo Instituto Nacional de Tecnologia da Informação. Disponível em: <http://www.iti.gov.br/icp-brasil/estrutura>. Acesso em 05 set. 2017.

${ }^{8}$ TEIXEIRA, Tarcisio. Curso de Direito e Processo Eletrônico: Doutrina, Jurisprudência e Prática. 3. ed. atual. e ampl. São Paulo: Saraiva, 2015. Disponível em: <https://app.saraivadigital.com.br/leitor/epub:165587>. Acesso em: 24 abr. 2017.
} 
a) autentica o documento e prova ao destinatário que o subscritor assinou-o;

b) impede a falsificação, pois somente o subscritor tem a chave privada que permite assiná-lo;

c) impede nova utilização da mesma assinatura, porque ela se amolda ao documento na sua essência;

d) impede que o documento seja modificado por qualquer de suas características depois de assinado pelo autor ${ }^{9}$.

A propósito, os artigos 193, caput, 205, §2 e 943, do Código de Processo Civil, versam sobre a validade jurídica da assinatura digital. Por sua vez, a certificação eletrônica é realizada por uma Autoridade Certificadora, que realizará a autenticação digital das assinaturas e dos documen$\operatorname{tos}^{10}$.

Finalmente, pode-se dizer que tais institutos fazem com que os cambiais virtuais adquiram a devida força probante para produzir direitos e obrigações entre as partes, até mesmo em eventual ação de execução devido à inadimplência, tópico a ser analisado posteriormente.

\section{O TÍTULO DE CRÉDITO VIRTUAL COMO EXCEÇÃO AO PRINCÍPIO CAMBIÁRIO DA CARTULARIDADE}

Do estudo dos títulos de crédito materiais deriva o princípio da cartularidade, oriundo da palavra "cártula", que significa o papel em que é lançado o ato cambiário típico de crédito. Uma das funções deste princípio é evitar o enriquecimento ilícito de terceiros, pois o documento original e em mãos traz a garantia de que a pessoa que requer a satisfação do direito e a que é detentora do título de crédito são as mesmas, podendo assim o credor, com a cártula em mãos, receber o que lhe é devido ${ }^{11}$.

Os títulos de créditos evoluíram simultaneamente com a sociedade, até a presente época, quando os meios eletrônicos passaram a substituir o papel e, por conseguinte, forçaram os cambiais a se adequarem à era digital. O artigo $889, \S 3^{\circ}$ do Código Civil, por sua vez, trouxe a norma que

\footnotetext{
${ }^{9}$ NEGRÃO, Ricardo. Manual de Direito Comercial e da Empresa: Títulos de Crédito e Contratos Empresariais. 3. ed. São Paulo: Saraiva, 2012. v. 2. Disponível em: <https://app.saraivadigital.com.br/leitor/epub:161737>. Acesso em: 22 abr. 2017.

${ }^{10}$ TEIXEIRA, Tarcisio. op. cit. nota 8. Disponível em: <https://app.saraivadigital.com.br/leitor/epub:165587>. Acesso em: 24 abr. 2017.

${ }^{11}$ COELHO, Fábio Ulhoa. Curso de Direito Comercial: Direito de Empresa. 19. ed. São Paulo: Saraiva, 2015. v. 1.p. 388.
} 
faltava para a validação dos títulos de créditos virtuais, configurando exceção ao princípio da cartularidade, ao passo que atualmente esta não depende mais da materialização do documento em papel.

Em suma, a informática desconstruiu os antigos padrões creditórios que vinham sendo estabelecidos desde a Idade Média, quando surgiram. Assim, os autores Marcelo M. Bertoldi e Maria Carla Pereira Ribeiro se manifestaram sobre o assunto:

Com o avanço da tecnologia, especialmente no que se refere à fa-
cilidade e rapidez na transmissão e armazenamento de dados por
meio de redes de computadores, aliado ao volume cada vez maior
de operações de crédito, mediante a massificação das relações co-
merciais, não podemos deixar de assinalar o fenômeno crescente da
criação e transmissão do crédito por meio magnético, a desafiar a
tradicional disciplina dos títulos de crédito. Os autores modernos
que se debruçam sobre as consequências da informática na teoria
dos títulos de crédito são unânimes em afirmar a necessidade de se
repensar os princípios informativos dos títulos de crédito, em espe-
cial o princípio da cartularidade, na medida em que convivemos
com títulos criados em meio eletrônico, como é o caso frequente e
cada vez mais disseminado da duplicata virtual, criada em meio
magnético pelo empresário-credor, que a transmite, também em
meio magnético, via internet, ao banco para que este proceda à co-
brança ${ }^{12}$.

Assim sendo, há que se falar na superação do princípio em estudo, pelo abandono do uso do papel, que trouxe consigo vantagens essenciais ao homem moderno, como a celeridade nas negociações, que agora se permitem ser virtuais, e não presenciais, e a preservação ambiental, com a diminuição do uso de papel no cotidiano das pessoas.

\section{$4 \quad$ PRINCIPAIS ESPÉCIES DE TÍTULO DE CRÉDITO QUE ADOTAM A VIRTUALIDADE}

\subsection{DUPLICATA VIRTUAL}

A duplicata é um título cuja previsão na legislação brasileira surgiu no Código Comercial de 1850, artigo 219, e conserva-se atualmente na Lei n. 5474 de 18 de julho de 1968 - Lei das Duplicatas. Possuem as duplicatas natureza comercial, ao passo que se encontram "relacionadas à

\footnotetext{
${ }^{12}$ BERTOLDI, Marcelo M e RIBEIRO, Marcia Carla Pereira. Curso Avançado de Direito Comercial. 6. ed. rev. atual e ampl. São Paulo: Revista dos Tribunais. 2011. Pág. 365.
} 
constituição, circulação e cobrança de crédito nascido de operações mercantis ou de contratos de prestação de serviços, desvencilhando-se dos aspectos fiscais que o cercavam" 13 , diferentemente da fase em que foram criadas, na qual possuíam a função de mero manejo de impostos.

É o título de crédito emitido pelo credor a partir de um contrato de compra e venda mercantil ou de prestação de serviços, ao comprador que realizará o pagamento. Em ambos os casos se admite a assistência eletrônica ${ }^{14}$, em prol da movimentação de riquezas mais rápida e eficaz.

A exibição em juízo da duplicata física é dispensável para o ajuizamento da ação de execução ${ }^{15}$, tornando perfeitamente possível que esse título de crédito seja emitido eletronicamente. Baseia-se no artigo 13, $§ 1$. $^{\circ}$ da Lei das Duplicatas a regra que possibilita, sem a devolução da duplicata original pelo credor, o protesto por indicação. Entende-se, portanto, que é viável, por analogia, a abrangência de tal norma também às duplicatas virtuais ${ }^{16}$.

Nesse sentido, o julgamento n. 1.024.691/PR, de Embargos de divergência, em que o relator do Superior Tribunal de Justiça, Ministro Raul Araújo, decidiu pela executoriedade da duplicata virtual:

EXECUÇÃO. DUPLICATA VIRTUAL. PROTESTO POR INDICAÇÃO Embora a norma do art. $13, \S 1 .^{\circ}$, da Lei 5.474/1968 permita o protesto por indicação nas hipóteses em que houver a retenção da duplicata enviada para aceite, $\mathrm{o}$ alcance desse dispositivo deve ser ampliado para harmonizar-se também com o instituto da duplicata virtual, conforme previsão constante dos arts. $8 .^{\circ}$ e 22 da Lei 9.492/1997. Quanto à possibilidade de protesto por indicação da duplicata virtual, deve-se considerar que o que o art. $13, \S 1 .^{\circ}$, da Lei 5.474/1968 admite, essencialmente, é o protesto da duplicata com dispensa de sua apresentação física, mediante simples indicação de seus elementos ao cartório de protesto. Daí, é possível chegar-se à conclusão de que é admissível não somente o protesto por indicação na hipótese de retenção do título pelo devedor, quando encaminhado para aceite, como expressamente previsto no referido

\footnotetext{
${ }^{13}$ COELHO, Fábio Ulhoa. op. cit. p.389, nota 11.

14 TEIXEIRA, Tarcisio. op. cit. nota 8. Disponível em: <https://app.saraivadigital.com.br/leitor/epub:165587>. Acesso em: 24 abr. 2017.

${ }^{15}$ SILVA, Marcos Paulo Félix da. Reflexões sobre a informatização da atividade e a desmaterialização dos títulos de crédito. São Paulo: Revista de direito bancário, do mercado de capitais e da arbitragem. v.6. n. 20. p. 226-236. abr./jun. 2003.

16 TEIXEIRA, Tarcisio. op. cit. nota 8. Disponível em: <https://app.saraivadigital.com.br/leitor/epub:165587>. Acesso em: 24 abr. 2017.
} 
artigo, mas também na de duplicata virtual amparada em documento suficiente. (EREsp 1.024.691/PR, 2. ${ }^{a}$ Seção, rel. Min. Raul Araújo, DJe 29.10.2012) ${ }^{17}$.

Assim, com julgados como este, favoráveis à execução das duplicatas virtuais, caem cada vez mais as teorias de obrigatoriedade de título executivo na forma de documento físico, ou seja, na forma de cártula, assentando a duplicata virtual como instrumento capaz de sustentar uma execução judicial.

\subsection{CHEQUE ELETRÔNICO}

Cheque é um título de crédito vinculado aos padrões fixados pelo Banco Central, que consiste em uma ordem de pagamento à vista sacada contra um banco em razão de fundos anteriormente depositados pelo sacador ou terceiro em sua conta na instituição bancária referida. Esse título é regido pela Lei n. 7357 de 02 de setembro de 1985 - Lei do Cheque ${ }^{18}$.

O uso do cheque convencional, ou seja, em papel, foi em sua maior parte substituído pelos cartões de débito e crédito, que nada mais representam do que a transferência virtual de fundos. Estes podem ser tidos como uma evolução dos cheques materiais na forma de pagamento à vista, podendo ser chamados de "cheques eletrônicos"19.

Os cartões magnéticos de débito e crédito possuem diferenças substanciais. Com o primeiro, através de um débito em sua conta corrente, o cliente poderá realizar pagamentos à vista, saques de dinheiro, transferências entre contas bancárias, dentre outras ações. Já em relação ao cartão de crédito não há dinheiro em conta, o que existe é um empréstimo feito pelo banco ao cliente, esperando que este pague as faturas em datas determinadas, para assim, o próximo limite de crédito ser liberado, inclusive com a opção de parcelamento das compras efetuadas.

A rápida popularização dos cartões deu-se por uma série de razões favoráveis ao cliente, como por exemplo a expansão das compras pela

\footnotetext{
${ }^{17}$ BRASIL. Superior Tribunal de Justiça. Embargos de Divergência no 1.024.691-PR. Embargante: Pawlowski e Pawlowski Ltda. e outros. Embargado: Petrobrás Distribuidora S/A. Relator: Min. Raúl Araújo. Paraná, 22 de agosto de 2012. Disponível em: <https://app.vlex.com/\#WW/vid/549828394>. Acesso em: 02 mai. 2017.

${ }^{18}$ CHAGAS, Edilson Enedino das. Direito Empresarial Esquematizado. 1. ed. São Paulo: Saraiva, 2014.

19 TEIXEIRA, Tarcisio. op. cit. nota 8. Disponível em: <https://app.saraivadigital.com.br/leitor/epub:165587>. Acesso em: 24 abr. 2017.
} 
internet, em que muitos fornecedores disponibilizam apenas as formas eletrônicas de pagamento; a impossibilidade de sustação por desacordo comercial; a diminuição do risco de inadimplência, como acontece com o cheque sem fundos; a segurança quanto ao porte de dinheiro em espécie, entre outras ${ }^{20}$.

\section{A VIABILIDADE DA EXECUÇÃO DO TÍTULO DE CRÉDITO IMATERIAL EM FACE DA INADIMPLÊNCIA}

Com o constante crescimento da realização de contratos virtuais, indaga-se, em primeiro lugar, se os títulos creditórios emitidos em tal modalidade teriam, frente ao ordenamento jurídico brasileiro, a mesma força probante dos documentos materiais. A resposta pode ser encontrada através da análise conjunta de algumas leis esparsas, bem como dispositivos localizados no Novo Código de Processo Civil.

Em primeiro lugar, entrou em vigor em março de 2007 a Lei 11419, de 19 de dezembro de 2006, sobre a informatização do processo judicial, que em seu artigo 11 já previa que os documentos produzidos eletronicamente e juntados aos processos eletrônicos, com a garantia da origem e de seu signatário, seriam considerados originais para todos os efeitos legais. Dispôs, ainda, em seu parágrafo $1^{\circ}$, que tais extratos digitais e documentos digitalizados teriam a mesma força probante dos originais. Além disso, a Lei 12682/12 recepcionou os arquivos digitais ao prever que a digitalização é a conversão da fiel imagem de um documento em código digital, com certificado emitido no âmbito da ICP BRASIL ${ }^{21}$.

O Código de Processo Civil de 2015, inclusive, dedicou uma seção exclusiva aos documentos eletrônicos, cujos artigos 439 a 441 tratam da possibilidade de sua utilização no processo convencional, verificada sua autenticidade, podendo também ser aplicadas a estes, no que couberem, as disposições referentes às provas documentais ${ }^{22}$.

No tocante ao comércio eletrônico, a efetuação da operação pelo consumidor presume $\mathrm{o}$ aceite das condições expostas de forma online pelo

\footnotetext{
20 TEIXEIRA, Tarcisio. op. cit. nota 8. Disponível em: <https://app.saraivadigital.com.br/leitor/epub:165587>. Acesso em: 24 abr. 2017.

${ }^{21}$ Id., Ibid. Disponível em: <https://app.saraivadigital.com.br/leitor/epub:165587>. Acesso em: 24 abr. 2017.

${ }^{22}$ Id., Ibid. Disponível em: <https://app.saraivadigital.com.br/leitor/epub:165587>. Acesso em: 24 abr. 2017.
} 
vendedor e, nesse caso, como a entrega dos produtos ocorre apenas através da confirmação do pagamento, geralmente realizado por meio dos cartões de débito ou crédito, ou pelo boleto bancário, não há que se falar em inadimplência ${ }^{23}$.

No entanto, pode ser que a operação ocorra presencialmente. Assim, as leis 5474/68 (Lei das Duplicatas) e 9492/97 (Lei de Protesto), autorizam a execução das duplicatas eletrônicas com base na apresentação do boleto bancário, desde que constem também as notas fiscais, comprovantes de entrega das mercadorias e os protestos por indicação ${ }^{24}$, para que a obrigação seja considerada líquida, certa e exigível, requisitos enumerados no artigo 783 do atual Código de Processo Civil, constituintes de título de crédito extrajudicial.

Em consonância, a decisão do Tribunal de Justiça de Minas Gerais:

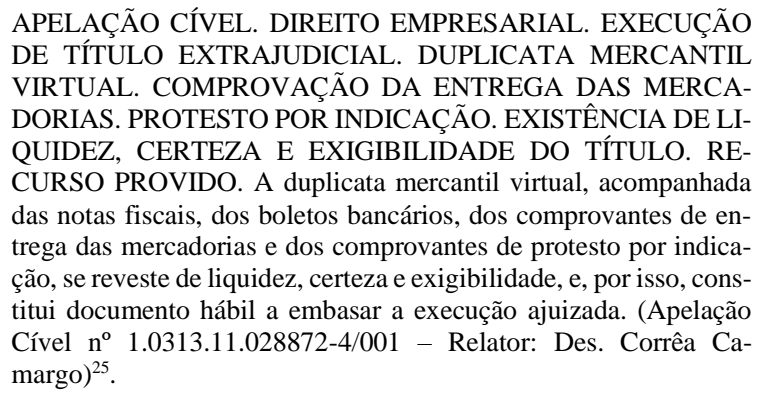

Em relação ao cheque eletrônico, por outro lado, não há inadimplência, visto que ao ser utilizado o cartão de débito, o valor é lançado na conta do emitente no mesmo instante e, caso o pagamento ocorra por meio do cartão de crédito, "a administradora pagará ao vendedor ainda que o

\footnotetext{
${ }^{23}$ DUARTE, Evangelina Castilho. Possibilidade jurídica de títulos de crédito virtuais ou escriturais. Rio de Janeiro: Revista Justiça \& Cidadania. 156. ed. p. 52-59. ago. 2013. Disponível em: <http:/www.editorajc.com.br/possibilidade-juridica-de-titulos-de-credito-virtuais-ou-escriturais/> Acesso em: 22 abr. 2017.

24Id., Ibid., p. 52-59.

${ }^{25}$ BRASIL. Tribunal de Justiça de Minas Gerais. Apelação Cível no 1.0313.11.028872-4/001. Apelante: Wave Surf e Street LTDA. Apelado: GSM Brasil LTDA. Relator: Des. Corrêa Camargo. Minas Gerais, 09 de abril de 2013. Disponível em: <http://www4.tjmg.jus.br/juridico/sf/proc_resultado2.jsp?listaProcessos=10313110288724001>. Acesso em: 02 de mai. 2017.
} 
cliente não pague a fatura do cartão" ${ }^{26}$. Consequentemente, também não há, portanto, até o momento, processos de execução desse tipo.

\section{CONSIDERAÇÕES FINAIS}

Do exposto acima, depreende-se que a era da informatização vem trazendo uma crescente tendência de predileção na utilização de títulos de crédito virtuais, em comparação aos títulos cartulares, tendo em vista que as duas espécies possuem igual validade e força probante e que os primeiros têm, ainda, a devida segurança proporcionada pela Infraestrutura de Chaves Públicas Brasileira e pelos sistemas de assinatura e certificação digital.

Outrossim, após discorrermos sobre os principais cambiais eletrônicos - a duplicata e o cheque -, ficou também definitivamente demonstrada a possibilidade de sua execução frente à hipótese de inadimplência do devedor.

Resta agora acompanhar as próximas mudanças legislativas no intuito de proporcionar a devida especificidade regulamentar que o tema merece, e que ainda hoje, infelizmente, tem deixado a desejar.

\section{REFERÊNCIAS}

BERTOLDI, Marcelo M e RIBEIRO, Marcia Carla Pereira. Curso Avançado de Direito Comercial. 6. ed. rev. atual e ampl. São Paulo: Revista dos Tribunais. 2011. Pág. 365.

BRASIL. Medida Provisória n 2.200-2, de 24 de agosto de 2001. Diário Oficial da República Federativa do Brasil, Poder Executivo, Brasília, DF, 27 de ago. 2001. Seção 1, p. 65.

Superior Tribunal de Justiça. Embargos de Divergência n ${ }^{\circ}$ 1.024.691-PR. Embargante: Pawlowski e Pawlowski Ltda. e outros. Embargado: Petrobrás Distribuidora S/A. Relator: Min. Raúl Araújo. Paraná, 22 de agosto de 2012. Disponível em: <https://app.vlex.com/\#WW/vid/549828394>. Acesso em: 02 mai. 2017.

. Tribunal de Justiça de Minas Gerais. Apelação Cível no 1.0313.11.028872-4/001. Apelante: Wave Surf e Street LTDA. Apelado: GSM Brasil LTDA. Relator: Des. Corrêa Camargo. Minas

\footnotetext{
${ }^{26}$ TEIXEIRA, Tarcisio. Direito Empresarial Sistematizado: Doutrina, Jurisprudência e Prática. 5. ed. São Paulo: Saraiva, 2016. p. 936.
} 
Gerais, 09 de abril de 2013. Disponível em: <http://www4.tjmg.jus.br/juridico/sf/proc_resultado2.jsp?listaProcessos=10313110288724001>. Acesso em: 02 de mai. 2017.

CHAGAS, Edilson Enedino das. Direito Empresarial Esquematizado. 1. ed. São Paulo: Saraiva, 2014.

COELHO, Fábio Ulhoa. Curso de Direito Comercial: Direito de Empresa. 19. ed. São Paulo: Saraiva, 2015. v. 1. p. 388-399.

DUARTE, Evangelina Castilho. Possibilidade jurídica de títulos de crédito virtuais ou escriturais. Rio de Janeiro: Revista Justiça \& Cidadania. 156. ed. p. 52-59. ago. 2013. Disponível em: <http://www.editorajc.com.br/possibilidade-juridica-de-titulos-de-credito-virtuais-ou-escriturais/> Acesso em: 22/04/2017.

NEGRÃO, Ricardo. Manual de Direito Comercial e da Empresa: Títulos de Crédito e Contratos Empresariais. 3. ed. São Paulo: Saraiva, 2012. v. 2.

RAFIH, Rhasmye El; CABRIOLI, José Vinicius. Origem e evolução dos títulos de crédito. Revista Jus Navigandi, ISSN 1518-4862, Teresina, ano 20, n. 4277, 18 mar. 2015. Disponível em: <https://jus.com.br/artigos/32014>. Acesso em: 24 abr. 2017.

SILVA, Marcos Paulo Félix da. Reflexões sobre a informatização da atividade e a desmaterialização dos títulos de crédito. São Paulo: Revista de direito bancário, do mercado de capitais e da arbitragem. v.6. n. 20. p. 226-236. abr./jun. 2003.

TEIXEIRA, Tarcisio. Curso de Direito e Processo Eletrônico: Doutrina, Jurisprudência e Prática. 3. ed. atual. e ampl. São Paulo: Saraiva, 2015.

Direito Empresarial Sistematizado: Doutrina, Jurisprudência e Prática. 5. ed. São Paulo: Saraiva, 2016.

TOMAZETTE, Marlon. A Duplicata Virtual. São Paulo: Revista dos Tribunais. v. 807. p. 725 740. jan. 2003.

VIVANTE, Cesare. Instituições de Direito Comercial. Trad. J. Alves de Sá. 3.ed. São Paulo: Livraria C. Ponto Teixeira \& C. ${ }^{a}$. 1928. p. 136. 